\title{
Optimization of Permanent Magnet Synchronous Motor with Halbach magnet
}

\author{
FAN Jian-jian ${ }^{1,2, a}$, WU Jian-hua ${ }^{2, b}$, \\ ${ }^{1}$ College of Electrical Engineering, Zhejiang University, Hangzhou, China \\ ${ }^{2}$ Zhejiang Xizi Forward Electrical Machinery Company LTD, Hangzhou, China. \\ afanjianjian_1204@hotmail.com, bemcad@163.com,
}

Keywords: Halbach magnet; permanent magnet synchronous motor; air-gap flux density;

\begin{abstract}
In order to optimize the air-gap flux density and reduce the difficulty of processing, a surface mounted partition between poles(PBP) Halbach magnet of permanent magnet synchronous motor is designed. The influence between the parameters of partition between poles Halbach magnet and the waveform of air-gap flux density are systematically analyzed. On this basis,the way to choose the best parameters of partition between poles Halbach magnet is proposed. The Correctness of the way to choose the result of optimization is verified, and the superiority of the partition between poles Halbach magnet is also verified further through FEA and experimentation respectively.
\end{abstract}

\section{Introduction}

The air-gap field distribution of servo PMSM is required sinusoidal; and the fundamental amplitude of the air-gap flux is required big enough to increase power density also; The Halbach magnet provides higher fundamental amplitude and lower harmonic distortion of air-gap flux as designed reasonably ${ }^{[1][2]}$. The halbach PMSM is lucubrated overseas, used as a motor/generator for a high-speed flywheel peak power buffer, high-performance linear and rotary servo motors, and passive magnetic bearings high speed motors/generates mainly ${ }^{[1]}$, and it is investigated in recent years in domestic, used as high speed energy storage flywhee, disk coreless PMSM and spherical $\mathrm{PMSM}^{[3]-[8]}$. The usage above are mainly in high speed occasion and hundred walts level, the halbach magnet is not used widely in a servo thousand walts occasion. In order to reduce the difficulty of processing, partition between rotor poles are required, so the traditional halbach magnet can't be used in this occasions, and the angle of patition between poles should be optimized.

In this paper, the influence of magnet's pole angle and charging angle on the air-gap flux density of surface mounted halbach magnetization PMSM are systematically analyzed. The performance of traditional and optimized halbach magnetization PMSM is contrasted through FEA and experimentation respectively, and the performance of the optimized halbach magnetization PMSM is enhanced by the large.

\section{Anaylsis of partion between poles halbach magnet's parameters}

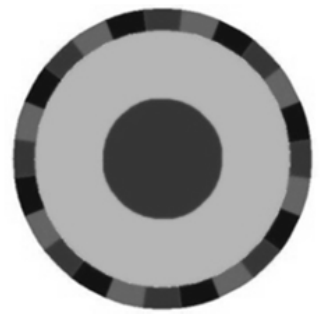

(a)

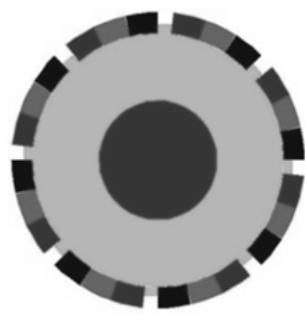

(b)

Fig. 1 Structure of two rotors

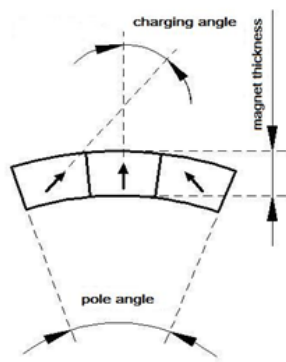

Fig. 2 Parameters of partition between poles Halbach magnet 
To PMSM composing of halbach magnet, the more number of magnets per pole leads to more sinusoidal air-gap flux density waveform and more complex manufacture techniques. Analysing PMSM consisting of 8 poles and 3 piece of magnet per pole, in order to take account of both air-gap flux density and manufacture difficulty. The traditional halbach PMSM structure is shown in Fig.1(a), in order to reduce the difficulty of mounting the surface mounted rotor magnet, partition between poles is applied in the servo PMSM used in numerical controlled machine, the halbach magnet with partition between poles' structure is shown in Fig.1(b). The main parameters of the PMSM is shown in Tab.1.

Parameters such as magnet thickness, magnet pole angle, magnet charging angle of the halbach magnet with partition between poles shown in Fig.1(b), shown in Fig.2.

Table 1 Main parameters of PMSM

\begin{tabular}{|c|c|c|c|}
\hline$\overline{\mathrm{PN}}$ & $1 \mathrm{kw}$ & Poles of rotor & 8 \\
\hline $\mathrm{nN}$ & 2500r/min & Length of iron & $60 \mathrm{~mm}$ \\
\hline $\begin{array}{c}\text { Outer diameter } \\
\text { of rotor }\end{array}$ & $102 \mathrm{~mm}$ & $\begin{array}{l}\text { Length of } \\
\text { air-gap }\end{array}$ & $1 \mathrm{~mm}$ \\
\hline $\begin{array}{c}\text { Inner diameter } \\
\text { of rotor }\end{array}$ & $64 \mathrm{~mm}$ & $\begin{array}{l}\text { Magnet } \\
\text { material }\end{array}$ & N35SH \\
\hline Slots of rotor & 18 & Iron material & DW470-50 \\
\hline
\end{tabular}

\section{The influence of magnet thickness on air-gap flux density}

PMSM consisted of traditional halbach magnet has characteristic that the pole angle is $45^{\circ}$ and the charging angle is $45^{\circ}$ also, but the halbach magnet analysed in this paper has partition between poles, so holding the magnet pole angle in $42^{\circ}$ and the charging angle in $45^{\circ}$, varying the magnet thickness from $2 \mathrm{~mm}$ to $6 \mathrm{~mm}$. The changing of the air-gap flux waveform with the magnet thickness was analysed through the way of FEA. The fundamental amplitude $B_{m 1}$ and the harmonic wave's amplitude $B_{m 2}, B_{m 3} \ldots B_{m k}$ of air-gap flux density was calculated through FFT. The total harmonic distortion of air-gap flux density was expressed by $K_{B}$ given in(1)

$K_{B}=\frac{\sqrt{B_{m 2}^{2}+B_{m 3}^{2}+\ldots+B_{m k}^{2}}}{B_{m 1}} \times 100 \%$

Fig.3(a)(b) show the fundamental amplitude and KB of air-gap flux density versus magnet thickness respectively. From Fig.3, it is shown obviously the fundamental amplitude is increasing with magnet thickness is increasing. The fundamental amplitude is small if the magnet thickness is smaller than 3mm, and its varying rate is becoming lower if the magnet thickness is bigger than $5 \mathrm{~mm}$, so it is recommended choosing magnet thickness from $3 \mathrm{~mm}$ to $5 \mathrm{~mm}$.

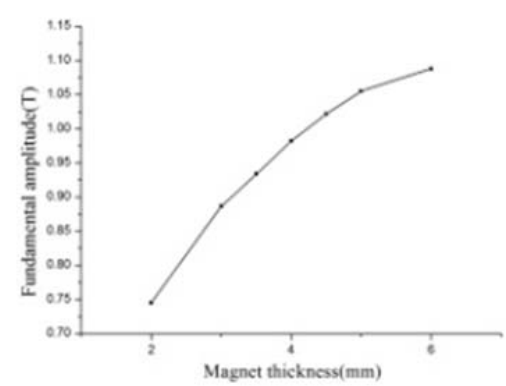

(a)

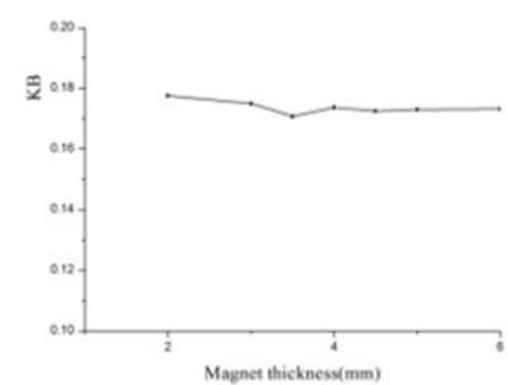

(b)

Fig. 3 Magnet-thick versus air-gap flux density

The influence of pole angle and charging angle of halbach magnet on air-gap flux density 
Holding the magnet thickness at $4.5 \mathrm{~mm}$, varying the pole angle from $30^{\circ}$ to $45^{\circ}$ and the charging angle from $0^{\circ}$ to $60^{\circ}$. The changing of the air-gap flux density with pole angle and charging angle is analysed through the way of FEA. Fig.4(a)(b) show the fundamental amplitude and $K_{B}$ of air-gap flux density versus pole angle and charging angle respectively.

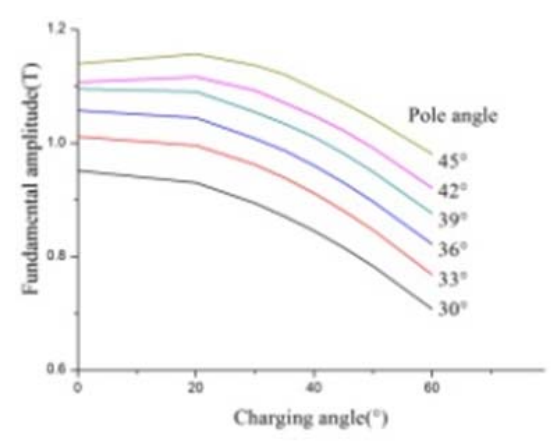

(a)

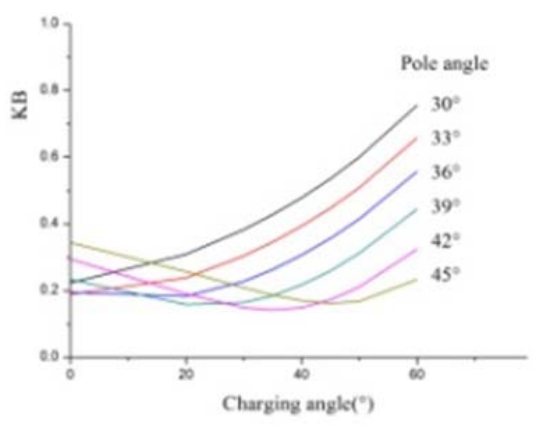

(b)

Fig. 4 Pole angle and charging included angle versus air-gap flux density

Table 2 Relative minimum of $K_{B}$ corresponding different pole angle of magnet

\begin{tabular}{rccc}
\hline $\begin{array}{c}\text { Pole } \\
\text { angle }\end{array}$ & $\begin{array}{c}\text { Charging } \\
\text { angle }\end{array}$ & $\begin{array}{c}\text { Fundamental } \\
\text { amplitude(T) }\end{array}$ & $K_{B}(\%)$ \\
\hline $39^{\circ}$ & $25^{\circ}$ & 1.0772 & 15.53 \\
$42^{\circ}$ & $35^{\circ}$ & 1.0705 & 14.15 \\
$45^{\circ}$ & $45^{\circ}$ & 1.0701 & 16.18
\end{tabular}

It is shown the fundamental amplitude decreases as pole angle increases in Fig.4(a), it is also shown in Fig.4(b) that when the pole angle is smaller than $36^{\circ}, K_{B}$ increases as the charging angle increases; and when the pole angle is bigger than $36^{\circ}, K_{B}$ increases ealy and decreases after the charging angle increases, and $K_{B}$ is minimal when the pole angle is $42^{\circ}$ and the charging angle is $35^{\circ}$. In order to require both relative maximum of fundamental amplitude and relative minimum of total harmonic distortion of air-gap flux density, the pole angle should be chosen from $39^{\circ}$ to $45^{\circ}$. In every different pole angle, the charging angle is different while getting the minimum of $K_{B}$ and the maximum of fundamental amplitude, such as while the pole angle is $39^{\circ}$,the charging angle should be chosen at $25^{\circ}$; and while the pole angle is $42^{\circ}$, the charging angle should be chosen at $35^{\circ}$; and while the pole angle is $45^{\circ}$ of the traditional halbach magnet PMSM, the charging angle should be chosen at $45^{\circ}$ as the traditional one. The fundamental amplitude of the magnet type above is shown in Tab.2, it is obviously shown that the three fundamental amplitude are almost same, it is also shown that $K_{B}$ of the three magnet types is increase early and decrease after as the pole angle increases. The performance of the traditional halbach magnet is not the best one , and the other two magnet types provide performance more superiority.

Table 3 Harmonic analysis results of two Halbach magnet

\begin{tabular}{|c|c|c|}
\hline & $\begin{array}{c}\text { Traditional } \\
\text { Halbach }\end{array}$ & $\begin{array}{c}\text { Optimized } \\
\text { Halbach }\end{array}$ \\
\hline $\begin{array}{c}\text { Fundamental } \\
\text { amplitude(T) }\end{array}$ & 1.0701 & 1.0823 \\
3rd harmonic & 0.0136 & 0.0063 \\
$\begin{array}{c}\text { amplitude(T) } \\
\text { th harmonic } \\
\text { amplitude(T) }\end{array}$ & 0.015 & 0.0132 \\
7th harmonic \\
amplitude(T) \\
$\begin{array}{l}\text { 9th harmonic } \\
\text { amplitude(T) }\end{array}$ & 0.0304 & 0.031 \\
\hline
\end{tabular}




\section{Analysis results of FEA and verification by experiment}

\section{Analysis results of FEA}

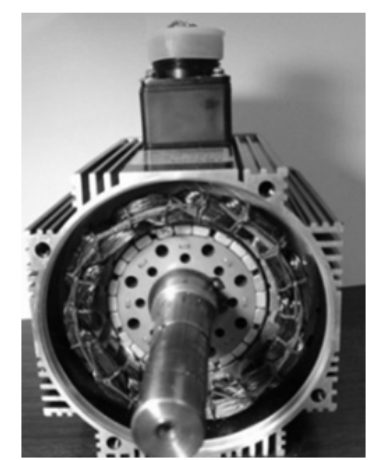

Fig. 5 End face of optimized motor

The PMSM consists of optimized partition between poles halbach magnet is analyzed through the way of FEA, then the waveform of the air-gap flux density is achieved. The contrasting FFT results of this magnet and the traditional halbach magnet's air-gap field distribution waveform is shown in Tab.3. It is obvious that the optimized magnet provides bigger fundamental amplitude and decreases the total harmonic distortion remarkably.

\section{Experimental results and validation}

The prototype of PMSM consists of optimized halbach magnet was trial-produced, the end face of the optimized PMSM is shown in Fig.5. The line EMF waveform was measured for contrasting analysis. On the condition of the same structure of stator and the same speed at 500rpm, the line-EMF waveform of PMSMs of the optimized and traditional halbach magnet are shown in Fig.6(a)(b), the results of FFT to these two waveform are shown in Tab.4. It is shown obviously in Tab.4 that the optimized magnet can offer larger fundamental amplitude of EMF and the total harmonic distortion of EMF is smaller than the traditional one.

Table 4 Harmonic analysis results of back EMF waveform of traditional and optimized partition between poles Halbach magnet

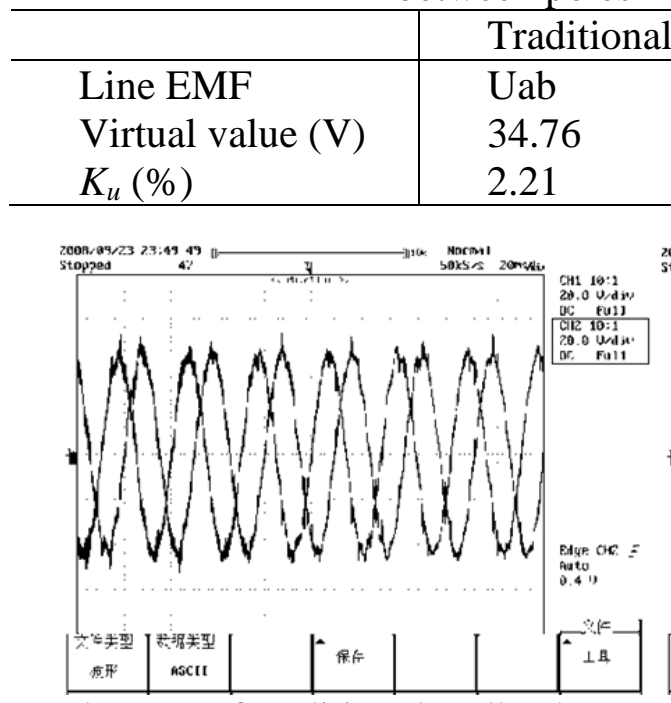

Fig. 6(a) Back EMF of traditional Halbach magnet

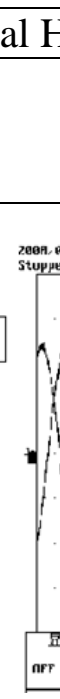

arr 回

\begin{tabular}{l|ll}
\hline lbach & \multicolumn{2}{|c}{ Optimized Halbach } \\
\hline Uca & Uab & Uca \\
34.88 & 35.27 & 35.45 \\
2.16 & 1.86 & 1.91 \\
\hline
\end{tabular}

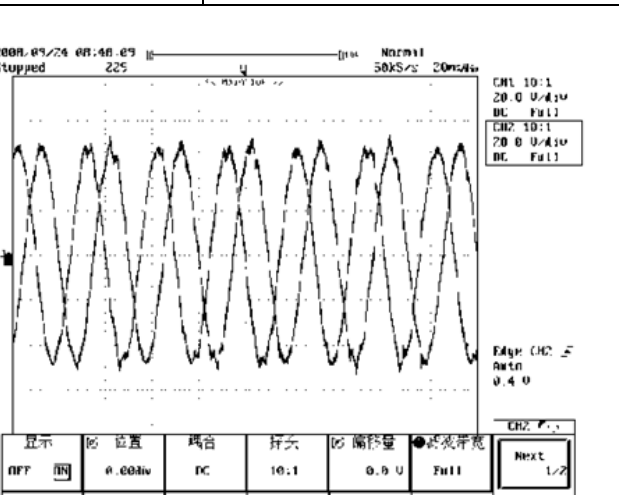

Fig. 6(b) Back EMF of optimized partition between poles Halbach magnet

\section{Conclusion}

In this paper, the influence of the partition between poles halbach magnet's parameters on the air-gap flux density is thoroughly analyzed, confirming this type of magnet can offer performance more superiority. FEA and experiment also validate the partition between poles halbach magnet can offer more superiority performance than the traditional halbach magnet: the fundamental amplitude 
of the air-gap flux density of the optimized magnet is bigger about $1 \%$ than the traditional one, $K_{B}$ of the optimized magnet is smaller about $12 \%$, the fundamental amplitude of the EMF is bigger about $1.5 \%$ than the traditional one, $K_{u}$ of the optimized magnet is smaller about $15 \%$ than the traditional one. It is verified ulteriorly that the partition between poles halbach magnet is compatibly applied in servo PMSM.

\section{References}

[1] Zhu Z Q, Howe D. Halbach permanent magnet machines and applications: a review[J]. IEE Proc. Electr. Power Appl., 2001, 148(4):299 308

[2] $\mathrm{Xu}$ Yanliang, Yao Fuan, Fang Jiancheng. Halbach array permanent magnet machine and performance comparison with the normal array one(I) $[\mathrm{J}]$. Transaction of China Electrotechnical Society, 2004,19(2):79-82.

[3] Xu Yanliang, Zhao Jianhui, Fang Jiancheng. Analysis and design of coreless permanent magnet brushless dc machine in high-speed energy storage flywheel application[J]. Transaction of China Electrotechnical Society, 2004, 19(12):24-28.

[4] $\mathrm{Xu}$ Feipeng, Li Tiecai. Simulation of new type of passive magnetic bearing using Halbach magnetic field[J]. Electric machines and control, 2007,11(5):538-541.

[5] Wang Xiaoyuan, Tang Renyuan, Du Jingjuan, Zhao Fang, Qi Lixiao. Optimization of Disk Coreless Permanent Magnet Synchronous Motor Based on Halbach-the Wedgy Airgap Motor[J]. Transaction of China Electrotechnical Society, 2007, 22(3):2-5.

[6] Xia Changliang, Li Hongfeng, Song Peng, Shi Tingna. Magnetic Field Model of a PM Spherical Motor Based on Halbach Array[J]. Transaction of China Electrotechnical Society, 2007, 22(7):126-130.

[7] Worbel, R. Mellor, P. H. Particle swarm optimization for the design of brushless permanent magnet machines[A]. 41st IAS Annual Meeting, Industry Applications Conference[C],2006:1891-1897.

[8] Jae Seok Choi, Jeonghoon Yoo. Design of a Halbach magnet array based on optimization techniques[J]. IEEE Trans.On magnetics,2008,44(10):2361 - 2366. 